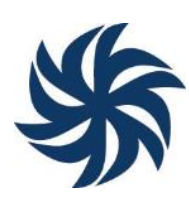

\title{
COMUNICAÇÃO POLÍTICA: A SAÚDE PÚBLICA NOS DISCURSOS DE POSSE DOS EX-MINISTROS DA SAÚDE DO BRASIL (1995-2016)
}

\author{
POLITICAL COMMUNICATION: PUBLIC HEALTH IN THE INAUGURATION \\ SPEECHES OF FORMER HEALTH MINISTERS OF BRAZIL (1995-2016)
}

\author{
COMUNICACIÓN POLÍTICA: DISCURSOS DE SALUD PÚBLICA DE LOS \\ EXMINISTROS DE SALUD EN BRASIL (1995-2016)
}

\author{
Danilo Fernandes Brasileiro ${ }^{1}$ \\ Maria Cristina da Costa Marques ${ }^{2}$
}

\begin{abstract}
Resumo: Objetivou-se identificar as transformações discursivas e compreender intencionalidades e influências ideológicas sobre o aperfeiçoamento da Saúde Pública brasileira, contidos nos discursos de posse de ex-ministros da Saúde (1995 -2016). Pesquisa histórica e documental, de abordagem qualitativa. Utilizou-se como referencial teórico-metodológico o método hermenêutico-dialético. Os discursos possuíram similaridades estruturais atinentes ao rito cerimonial simbólico em que foram proferidos, classificados em: conceitos depreendidos; desafios identificados e propostas definidas. Não se identificou grandes rupturas ideológicas sobre saúde, entre as plataformas de governos (PT e PSDB), apenas enfoques diferentes em um período de consolidação e aperfeiçoamento do SUS, com manutenção de uma linha de gestão operacional similar, distanciamento paulatino do projeto da Reforma Sanitária Brasileira e subordinação à lógica econômica de produção de saúde.
\end{abstract}

Palavras-chave: Discursos; História; Saúde Pública; Política; Política de Saúde.

Abstract: The objective was to identify the discursive transformations and understand intentions and ideological influences on the improvement of Brazilian Public Health, contained in the inaugural speeches of former Health Ministers (1995-2016). Historical and documentary research, with a qualitative approach. The hermeneutic-dialectic method was used as a theoretical-methodological framework. The speeches had structural similarities related to the symbolic ceremonial rite in which they were delivered, classified into: understood concepts; identified challenges and defined proposals. No major ideological ruptures on health were identified between government platforms (PT and PSDB), only different approaches in a period of consolidation and improvement of the SUS, with maintenance of a similar operational management line, gradual distancing from the project of Brazilian Health Reform and subordination to the economic logic of health production.

Keywords: Speeches; History; Public Health; Politics; Health police.

Resumén: El objetivo fue identificar las transformaciones discursivas y comprender las intenciones e influencias ideológicas sobre el mejoramiento de la Salud Pública brasileña, contenidas en los discursos inaugurales de los exministros de Salud (1995-2016). Investigación histórica y documental, con enfoque cualitativo. Se utilizó el método hermenéutico-dialéctico como marco teórico-metodológico. Los discursos tuvieron similitudes estructurales relacionadas con el rito ceremonial simbólico en el que fueron pronunciados, clasificados en: conceptos entendidos; retos identificados y propuestas definidas. No se

\footnotetext{
${ }^{1}$ Mestre em Ciências pela UNIFESP. Aluno de doutorado da Faculdade de Saúde Pública da Universidade de São Paulo (USP). Orcid: http://orcid.org/0000-0002-3905-7579 E-mail: danilo.brasileiro@ hc.fm.usp.br

2 Doutora em História Social e professora do Departamento de Gestão e Política da Faculdade de Saúde Pública da Universidade de São Paulo (USP). http://orcid.org/0000-0002-7461-3710 E-mail: mcmarques@usp.br
} 
identificaron grandes rupturas ideológicas en salud entre plataformas de gobierno (PT y PSDB), solo enfoques diferentes en un período de consolidación y mejora del SUS, con mantenimiento de una línea de gestión operativa similar, distanciamiento gradual del proyecto de Salud Brasileña. Reforma y subordinación a la lógica económica de la producción sanitaria.

Palabras clave: Discursos; Historia; Salud Pública; Política; Politica sanitaria.

\section{INTRODUÇÃO}

Discurso, por definição, pode ser entendido como um modo particular de unidade linguística e uma focalização no uso da língua (SCHIFFRIN, 1994). A ideia de discurso fora do campo da linguística entra em ressonância com determinadas correntes construtivistas, em particular, a sociologia do conhecimento. Em diferentes vertentes, é concebido como uma organização além da frase, uma forma de ação regida por normas, de caráter interativo e contextualizado, assumido por sujeitos no âmago das relações interdiscursivas, uma vez que considera-se que sua construção é socialmente dependente (MAINGUENEAU, 2014).

Nessa perspectiva conceitual e epistêmica, o discurso tem "efeitos da verdade que em si não são verdadeiros e nem falsos" (FOUCAULT, 1982, p. 7), pois se trata de:

Um bem - finito, limitado, desejável, útil - que tem suas regras de aparecimento e também suas condições de apropriação e de utilização: um bem que coloca, por conseguinte, desde sua existência (e não simplesmente em suas “aplicações práticas”), a questão do poder; um bem que é, por natureza, o objeto de uma luta, e de uma luta política (FOUCAULT, 2007, p. 136-137).

Dessa forma parte-se do pressuposto que "Qualquer enunciado, por mais inocente que seja, pode ter um sentido político a partir do momento em que a situação autorizar. Não é, portanto, o discurso que é político, mas a situação de comunicação que assim o torna" (CHARAUDEAU, 2018, p. 39). Nesse sentido, entre os lugares onde se produz esse pensamento, há aquele que considera o discurso um "ato de comunicação", como os que se estruturam em eventos governamentais, por exemplo, pois "o discurso político resulta da mistura sutil entre a palavra que deve fundar a política e a que deve gerir a política" (CHARAUDEAU, 2018, p. 45).

No contexto de aperfeiçoamento e gestão do Sistema Único de Saúde (SUS), de março de 1990 a abril de 2016, 18 atores políticos, em mandatos de cinco presidentes distintos, foram ministros da saúde (MINISTÉRIO DA SAÚDE, 2014). Sua permanência no cargo variou de menos de um ano (Negri, Felipe e Álvares) a quase quatro (Serra e Temporão) (MINISTÉRIO DA SAÚDE, 2014), e todos cumpriram o rito cerimonial de transmissão de cargo, regimentado pela Lei n. 70.274/1972 (BRASIL, 1972).

No caso específico das cerimônias de transmissão de posse entre ministros da saúde no Brasil, um dos principais momentos é a enunciação institucional discursiva, ou seja, o discurso de posse, em que ideias e posicionamentos são verbalizadas ao público, sempre em uma lógica de projeção de ações que em tese garantirá o bem comum social, uma vez que o decisor através do discurso proferido, “[...] não apenas elaborou um projeto no qual está inscrito o fim a atingir, 
mas que, além disso, tomou a decisão de engajar-se na concretização dessas ações pela qual ele é, a partir desse momento, totalmente responsável" (CHARAUDEAU, 2018,p.17).

Assim, considerando o conteúdo discursivo e sua representatividade no campo políticoideológico (PIMENTEL; PANKE, 2020), bem como suas atuações e consequentes colaborações em torno do aperfeiçoamento do SUS nos últimos trinta anos, busca-se com o presente estudo analisar os discursos posse dos Ex-ministros da Saúde do Brasil, entre os anos de 1995 a 2016.

A análise objetiva contribuir com substratos teóricos para compreender as mudanças discursivas, suas intenções e a influência da comunicação política na consolidação e no aperfeiçoamento do SUS e, consequentemente, na Saúde Pública brasileira, havendo poucos estudos dedicados ao tema, (PIMENTEL; PANKE, 2020; IACOMINI JUNIOR; CARDOSO; PRADO JUNIOR, 2018; PISTORI, 2018), uma vez que nenhum se dedicou à análise específica de discursos dos executivos federais da saúde, seja na posse, transmissão de posse e em inúmeras outras situações possíveis.

\section{MÉTODO}

Trata-se de um estudo histórico e documental de abordagem qualitativa. O recorte temporal do estudo é datado do ano de 1995 a 2016, justificado pelo fato de que durante esse período, em que três diferentes presidentes governaram o Brasil e 12 ministros também diferentes atuaram à frente da pasta da saúde (BRASIL, 2014), houve uma estabilidade democrática e continuidade nas ações do Ministério da Saúde, o que possibilitou a gênese, a implementação e o aperfeiçoamento de inúmeras ações e programas federais de saúde no âmbito do SUS.

O corpus documental utilizado se constituiu pelos discursos de oito ex-ministros da saúde, proferidos durante cerimônia de posse do cargo. Esses discursos foram selecionados e impressos subsequentemente, após consultas digitais à Biblioteca da Universidade Federal de Londrina, Biblioteca do Ministério da Saúde e Site do Ministério da Saúde, entre os anos de 2018 e 2020.

Embora o recorte temporal esteja determinado entre 1995 a 2016, os discursos de posse analisados referem-se à oito ex-ministros da saúde (quadro 1), sendo que discursos de ministros que atuaram nesse período, como Adib Jatene, José Carlos Seixas, José Saraiva Felipe e José Agenor não foram incluídos, uma vez que os pesquisadores, apesar de constantes buscas, não conseguiram obter as cópias dos discursos dos ex-ministros supracitados.

O referencial teórico-metodológico de análise foi o método hermenêutico-dialético (MINAYO, 2006). O método sustenta a ação do pesquisador frente à análise do discurso, uma vez que transita e opera a partir de características singulares da hermenêutica - cuja estrutura atinge sua concreção na abordagem histórica, permitindo compreensão de textos nas condições em que surgem - e pela dialética -, partindo da premissa de que a linguagem é um instrumento de comunicação em que significados aparentemente semelhantes expressam e escondem a realidade conflitiva das desigualdades, da dominação, da exploração e da resistência e da 
conformidade (MINAYO, 2006).

Em sua proposta, Minayo (2006) segmenta o procedimento analítico em três fases: (1) ordenação dos dados, (2) classificação dos dados e (3) análise final.

Assim, com oito discursos impressos em mãos, foi realizada a organização e ordenamento dos mesmos por cronologia, seguida de leitura analítica, o que permitiu uma classificação prévia, evidenciando superficiais diferenciações e homogeneidades. Após a ordenação, o processo de classificação foi iniciado com leitura horizontal exaustiva de cada um dos discursos, de modo separado, discriminando em arquivo digital designado a cada um dos discursos, as impressões iniciais, permitindo a construção e registros de categorias empíricas.

Finalizado o processo de leitura horizontal, iniciou-se o procedimento de leitura transversal. Nessa etapa, foram identificadas e criadas unidades de sentidos, baseadas em temas mais relevantes, presentes e comuns em todos os oito discursos, o que permitiu a extração de excertos referentes aos seus respectivos temas, posteriormente compilados e por sua vez reagrupados e categorizados.

Ao fim da etapa de classificação, com as categorias centrais definidas, foi desenvolvido o processo de análise de perspectiva crítica acerca dos achados, cotejando os mesmos com a literatura científica pertinente. O Quadro 1 apresenta a lista dos ministros da Saúde do Brasil incluídos no estudo. 
Quadro 1 - Galeria de ministros da Saúde do Brasil incluídos no estudo

\begin{tabular}{|c|c|c|c|c|}
\hline Nome & $\begin{array}{c}\text { Período no } \\
\text { ministério }\end{array}$ & Partido & $\begin{array}{l}\text { Presidente(a) da } \\
\text { República }\end{array}$ & DADOS BIOGRÁFICOS \\
\hline $\begin{array}{l}\text { Carlos César } \\
\text { Silva de } \\
\text { Albuquerque }\end{array}$ & $\begin{array}{l}13 / 12 / 1996 \\
30 / 03 / 1998\end{array}$ & PSDB & $\begin{array}{c}\text { Fernando Henrique } \\
\text { Cardoso }\end{array}$ & $\begin{array}{c}\text { Nascido em Barra do Ribeiro-RS (19/07/1940). } \\
\text { Graduado na Faculdade de Medicina da Universidade } \\
\text { Federal do Rio Grande do Sul (1966). Foi presidente do } \\
\text { Hospital das Clínicas de Porto Alegre. Faleceu em } \\
\text { 18/03/2005. }\end{array}$ \\
\hline José Serra & $\begin{array}{c}31 / 03 / 19982 \\
0 / 02 / 2002\end{array}$ & PSDB & $\begin{array}{l}\text { Fernando Henrique } \\
\text { Cardoso }\end{array}$ & $\begin{array}{l}\text { Nascido em São Paulo-SP (19/03/1942). Graduado em } \\
\text { Engenharia Civil na Universidade de São Paulo (1964). } \\
\text { Foi deputado federal e governador do estado de São } \\
\text { Paulo. Atualmente, é senador da República. }\end{array}$ \\
\hline Barjas Negri & $\begin{array}{c}21 / 02 / 20023 \\
1 / 12 / 2002\end{array}$ & PSDB & $\begin{array}{l}\text { Fernando Henrique } \\
\text { Cardoso }\end{array}$ & $\begin{array}{l}\text { Nascido em São Paulo-SP (08/12/1950). Graduado em } \\
\text { Economia, com mestrado e doutorado pela UNICAMP- } \\
\text { SP. Foi secretário executivo do FNDE, secretário } \\
\text { executivo do Ministério da Saúde e prefeito da cidade } \\
\text { de Piracicaba. }\end{array}$ \\
\hline $\begin{array}{l}\text { Humberto } \\
\text { Sergio Costa } \\
\quad \text { Lima }\end{array}$ & $\begin{array}{c}01 / 01 / 20030 \\
8 / 07 / 2005\end{array}$ & PT & $\begin{array}{l}\text { Luís Inácio Lula da } \\
\text { Silva }\end{array}$ & $\begin{array}{l}\text { Nascido em Campinas-SP (07/07/1957). Graduado em } \\
\text { Jornalismo e em Medicina, com pós-graduação em } \\
\text { Clínica Médica (FCM-UPE) e em Medicina Geral } \\
\text { Comunitária e Psiquiatria (UFPE). Foi vereador e } \\
\text { secretário de Saúde de Recife-PE, deputado estadual e } \\
\text { federal. Atualmente, é senador da República. }\end{array}$ \\
\hline $\begin{array}{l}\text { José Gomes } \\
\text { Temporão }\end{array}$ & $\begin{array}{c}16 / 03 / 20073 \\
1 / 12 / 2010\end{array}$ & PMDB & $\begin{array}{l}\text { Luís Inácio Lula da } \\
\text { Silva }\end{array}$ & $\begin{array}{c}\text { Nascido em Merufe, Portugal (20/10/1951). Graduado } \\
\text { em Medicina (UFRJ), mestre em Saúde Pública e } \\
\text { doutor em Saúde Coletiva. Foi secretário nacional de } \\
\text { Atenção à Saúde (SAS) em 2005. Atualmente, é } \\
\text { professor titular e pesquisador aposentado da Fundação } \\
\text { Oswaldo Cruz. }\end{array}$ \\
\hline $\begin{array}{l}\text { Alexandre } \\
\text { Rocha Santos } \\
\text { Padilha }\end{array}$ & $\begin{array}{c}01 / 01 / 20110 \\
2 / 02 / 2014\end{array}$ & PT & $\begin{array}{l}\text { Dilma Vana } \\
\text { Rousseff }\end{array}$ & $\begin{array}{c}\text { Nascido em São Paulo-SP (14/09/1971). Graduado na } \\
\text { Faculdade de Ciências Médicas da UNICAMP, com } \\
\text { especialização em Infectologia na FMUSP. Foi diretor } \\
\text { nacional de Saúde Indígena do Ministério da Saúde } \\
\text { (2004-2005). Atualmente, é deputado federal por São } \\
\text { Paulo. }\end{array}$ \\
\hline $\begin{array}{l}\text { Ademar Arthur } \\
\text { Chioro dos Reis }\end{array}$ & $\begin{array}{c}03 / 02 / 20140 \\
2 / 10 / 2015\end{array}$ & PT & $\begin{array}{l}\text { Dilma Vana } \\
\text { Rousseff }\end{array}$ & $\begin{array}{l}\text { Nascido em Santos-SP (05/12/1963). Graduado em } \\
\text { Medicina e mestre em Saúde Coletiva pela Faculdade } \\
\text { de Ciências Médicas da Unicamp e doutor em Saúde } \\
\text { Coletiva pela UNIFESP. Foi diretor do Departamento } \\
\text { de Atenção Especializada do Ministério da Saúde } \\
\text { (2003-2005) e secretário de Saúde de São Bernardo do } \\
\text { Campo-SP. Atualmente, é professor da Escola Paulista } \\
\text { de Medicina/UNIFESP. }\end{array}$ \\
\hline $\begin{array}{c}\text { Marcelo Costa e } \\
\text { Castro }\end{array}$ & $\begin{array}{c}\text { 02/10/20152 } \\
7 / 04 / 2016\end{array}$ & PMDB & $\begin{array}{l}\text { Dilma Vana } \\
\text { Rousseff }\end{array}$ & $\begin{array}{l}\text { Nascido em São Raimundo Nonato-PI (09/06/1950). } \\
\text { Graduado na Faculdade de Medicina da Universidade } \\
\text { do Piauí e doutor em Psiquiatria pela UFRJ. Foi } \\
\text { deputado estadual e federal por inúmeros mandatos. } \\
\text { Atualmente, é senador da República. }\end{array}$ \\
\hline
\end{tabular}

Fonte: Brasil, 2014.

\section{RESULTADOS E DISCUSSÃO}

Os discursos guardaram similaridades estruturais, atinentes ao rito cerimonial para o qual foram elaborados. Seguiram uma lógica em que sequencialmente apresentavam os agradecimentos ao presidente, acenos à aliados políticos e à órgãos representativos, lisonja acerca da indicação, conceitualização de questões atinentes à saúde, gestão e SUS, além da discriminação 
de desafios e propositura de ações para enfrentá-los.

Assim, foi possível construir, descrever e analisar três categorias temáticas: conceitos depreendidos, desafios identificados e propostas definidas.

\title{
3.1 Conceitos depreendidos
}

O termo "conceito", com origem no latim conceptus, significa "coisa concebida ou formada na mente", muito embora na linguagem natural tenha diferentes acepções - de noção, juízo, opinião, ideia ou pensamento -, além de designar um fenômeno que é apreendido pelo indivíduo, e sua função é determinada por um contexto (MACULAN; LIMA, 2017; FERRATERMORA, 2004). Além dessa definição, pode-se dizer que conceito é "todo processo que torne possível a descrição, a classificação e a previsão dos objetos cognoscíveis" (ABBAGNANO, 1998, p. 164).

Isto posto, conceito de saúde esteve presente em todos os discursos, e destacamos alguns que indicam diferentes perspectivas nas quais se deveria pautar a ação do representante. Albuquerque, com um discurso mais protocolar, de texto curto, com pouco mais de seiscentas palavras, em que enfocou temas como descentralização, saúde suplementar e educação, indicou uma perspectiva "globalizante", tributária da lógica econômica:

Ao encararmos problemas da Saúde nessa visão globalizante, inseridas nas perspectivas socioeconômicas, estaremos criando condições para fazer o sistema de saúde participar dessa nova fase que o país está vivendo em todos os setores, com a implantação do Plano Real e o governo de vossa excelência (ALBUQUERQUE, 1997, p. 1).

Negri (2002) fez um discurso sintético e pragmático, com aproximadamente mil palavras, falou em atingir metas e causar impacto na saúde, enquanto Serra (1998, p. 1), num discurso mais longo e elaborado, com cerca de três mil e seiscentas palavras e quinze princípios norteadores, trouxe um conceito ampliado de saúde pública:

\begin{abstract}
A saúde de um povo, ou pelo menos o que um povo pensa sobre o estado geral de sua própria saúde, reflete de forma extremamente sensível os mais diversos aspectos da sociedade. Incidem sobre as condições de saúde fatores tão dispares quanto o nível de emprego, as taxas de salários, a inflação, as formas de organização familiar, os acidentes de trânsito, os investimentos em saneamento, os hábitos de higiene familiar, fenômenos ambientais e, particularmente, um conjunto de ações que podemos denominar políticas de saúde, em cujo vértice encontra-se o Ministério da Saúde.
\end{abstract}

Lima apresentou um discurso com cerca de duas mil e setecentas palavras, de modo que conceituou a saúde como resultante da lógica ideológica do governo que representava:

Assumo o Ministério da Saúde com a visão clara que temos todos de que a saúde é algo que resulta de um conjunto de ações, ações que esse governo já manifestou a sua intenção a sua determinação de realizar as ações na área da alimentação, da moradia, do trabalho, do salário, do lazer, da cultura e também 
das ações de saúde onde nós vamos trabalhar (LIMA, 2003, p. 5).

Temporão desenvolveu um discurso com forte influência programática, com cerca de duas mil e setecentas palavras e, por sua vez aproximou a saúde da determinação social: "existem fortes evidências científicas de que países que apresentam perfis de equidade em relação ao padrão de vida referido a classes, gênero e raça, apresentam também melhor nível de saúde" (TEMPORÃO, 2007, p. 7).

Castro, apresentou um discurso com cerca de quatro mil palavras, conceituando a saúde como um direito: "Um orgulho brasileiro é ter a saúde sido reconhecida pela Constituição como direito e ter consagrado em suas estruturas a participação social, que atua junto ao Poder Público na definição de suas políticas" (CASTRO, 2015, p. 2-3).

Padilha (2011, p. 4), com cerca de nove mil e novecentas palavras, apontou-a como condição para o avanço nacional: “[...] às vezes temos esse sentimento de que a saúde não está no centro da agenda de desenvolvimento deste país", e Chioro dos Reis (2014, p. 2), com um discurso longo, de aproximadamente cinco mil e oitocentas palavras, postulou o compromisso de "[...] defender a vida, mais saúde, mais democracia e mais liberdade".

O conceito de saúde aparece em diferentes perspectivas, refletindo a concepção dos sujeitos do discurso, mas também sua agenda político-governamental, ou seja, a lógica socioeconômica ou a global, o Estado como produtor de saúde, esta como condição do desenvolvimento ou alinhada constitucionalmente e, por fim, a perspectiva da determinação social como pensamento dialético.

Embora apenas em linhas gerais, Albuquerque $(1997$, p. 1) se posicionou frente ao SUS:

[...] o sistema de saúde no Brasil caracteriza-se pelo modelo médico-curativo, centrado ao tratamento da enfermidade e, em torno do qual, constitui-se uma enorme estrutura burocrática, que acabou por distanciar o recurso da necessidade, o paciente da terapia e o cidadão da saúde.

E Negri (2002, p. 2-3) afirmou: “[...] a tarefa de construção do Sistema Único de Saúde não é uma bandeira de alguns, como muitos ainda fazem crer, mas de todos aqueles que aliam a capacidade de compreender as dificuldades que atingem a população à competência para enfrentálas". Assim, indicou, já no discurso de posse, que a defesa do SUS não era incumbência/privilégio de alguns, ou seja, estrategicamente, buscava se posicionar e legitimar como um dos "novos construtores" do SUS, ao lado aqueles que participaram do projeto da Reforma Sanitária Brasileira, movimento nascido no seio dos movimentos sociais, estudantil, acadêmico, sindical e de profissionais de saúde, incorporado pelo Estado a partir da Constituição de 1988 (PAIM, 2017). Ademais, essa afirmação parece ser uma expressão político-ideológica de aproximação com a lógica partidária e a agenda do governo FHC.

Nesse governo, o conceito de SUS foi paulatinamente sendo construído numa lógica inaugural de desbravamento, da descoberta de um terreno fecundo, mas que demandava atitudes 
concretas, alinhadas a uma perspectiva administrativa gerencial, posto que o funcionamento desse sistema era considerado ineficiente e burocrático, cabendo aos gestores torná-lo moderno e eficiente.

Lima (2003, p. 6) pontuou a necessidade de que o SUS tornasse uma "política hegemônica", pois era "exemplo da reforma que precisa ser feita em muitos países", enquanto José Gomes Temporão (2007, p. 4) entendeu que "O SUS é uma política de Estado, portanto, suprapartidária", até porque "O momento que o SUS atravessa hoje está vinculado à dinâmica do Complexo Industrial da Saúde, composta por processos de estruturação e funcionamento que podem ser contraditórios e paradoxais a uma política social cujas premissas são a universalidade e a equidade".

Padilha (2011, p. 4) apontou: “[...] temos plena consciência da importância do SUS e da área da saúde para a agenda nacional de desenvolvimento do País, temos plena consciência de que não existiria redução da desigualdade social sem esse grande projeto de inclusão social que é o SUS [...]".

Chioro e Castro apresentaram conceitos diferentes do SUS: "Afinal, o SUS é um patrimônio, um marco civilizatório para a produção de uma sociedade mais saudável, justa e solidária. Mas é preciso lembrar que se trata de um projeto ético-político em disputa, não está dado" (REIS, 2014, p. 13), e "o SUS é o retrato da nova forma de se governar, onde nada é sozinho e tudo é composto no interesse público" (CASTRO, 2015, p. 6).

Entre os ex-ministros do governo Lula, o conceito de SUS foi alinhado a qualificações como complexidade e credibilidade, sendo definido como exemplo de política de saúde para outros países e como uma política social inclusiva, suprapartidária, no bojo socioeconômico de produção de saúde complexo e paradoxal. No governo Dilma, os ex-ministros reiteraram a importância do modelo universal com uma crítica branda, aproximando sua definição do patrimônio social, de um projeto inclusivo, marco civilizatório de interesse público, e Chioro acrescentou que o sistema ainda não estava consolidado, mas em constante disputa ético-política.

Na relação entre essas representações ministeriais, cabe lembrar a crítica de Jairnilson Paim (2017), em seu já histórico trabalho sobre a Reforma Sanitária Brasileira, que reforça a concepção de que ela foi, e continua sendo, uma luta contra-hegemônica, em que governos, inclusive de esquerda, ao longo de anos de gestão, flexibilizaram lhe princípios e diretrizes para ajustá-la a imperativos econômicos e demandas coorporativas.

\subsection{Desafios identificados}

A comunicação nos discursos políticos aponta frequentemente a narrativa de desafios a ser superados pelo projeto de trabalho do sujeito do discurso - os ministros da Saúde. Assim, os desafios que emergem na análise discursiva permitem vislumbrar estratégias ou pontos-chave a ser priorizados na gestão. 
Albuquerque (2017, p. 1) ponderou que "A magnitude do desafio desautoriza a eloquência retórica, as promessas fáceis e o otimismo inconsequente", mas logo acrescentou: "Reafirmamos, nessa oportunidade, a convicção de que é possível ao setor público oferecer um serviço de saúde digno, eficiente e de qualidade".

Serra (1998, p. 1/3), por sua vez, indicou: “[...] o desafio de hoje, que enfrento a partir dos 56 anos de idade, é o maior de todos", uma vez que "O que precisamos é que funcione melhor. Aliás, esta é a síntese do nosso programa: fazer os serviços de saúde funcionarem melhor", enquanto Negri $(2002$, p. 2) alegou que seria "[...] preciso estar constantemente alerta para enfrentar novos desafios, e disposto a superá-los. Acima de tudo, a luta para ampliar os recursos públicos para a saúde jamais deve ser abandonada". Nota-se que os ex-ministros do governo FHC alinharam a gestão burocrática e ineficiente como os principais desafios identificados, sempre referindo lógicas da administração gerencial, regidas por qualificadores como qualidade, eficiência e racionalidade.

Nas afirmações sobre a administração pública, era imperativo transformar a cultura burocrática do Estado numa cultura gerencial, parte da agenda do então Ministro da Administração Federal e da Reforma Administrativa, Bresser Pereira, que em 1995 apresentou o Plano Diretor Reformista do Estado, viabilizado em emenda constitucional de 1998. Entre as premissas dessa reforma, estava a necessidade de mudar o modelo da administração pública brasileira vigente até então (PAULA, 2005).

Lima (2003, p. 12) afirmou que, frente ao desafio, deveria “[...] corresponder não só à confiança do presidente, que me deu essa grande responsabilidade, mas à confiança do povo brasileiro, que quer, entre outras coisas, uma condição de vida e de saúde digna”.

E Temporão (2007, p. 2/4), que, “[...] ao assumir a pasta do Ministério da Saúde do Brasil, estou de imediato desafiado a articular a compreensão dos determinantes da saúde da população brasileira, com o conjunto de providências e ações possíveis dentro da governabilidade setorial", pois "O governo do Presidente Lula tem este compromisso e enfrentará esse desafio".

Certamente, nesse período, a agenda federal de saúde se aproximou às vezes de temas da Reforma Sanitária, em diálogo com a agenda desenvolvimentista do governo Lula, o discurso de posse e gestão de Temporão trouxe um projeto próximo à concepção sanitarista, à ideia de produção social do processo saúde-doença e à necessidade de estabelecer mecanismos para promover a saúde (ARAÚJO, 2017).

Padilha (2011, p. 4) considerou desafio maior inserir o SUS como estratégia necessária à solidez de um amplo projeto desenvolvimentista:

Queremos que o conjunto do povo brasileiro se sinta parte dessa quinta economia do mundo. E ele não vai se sentir parte se não tiver uma saúde que se sinta uma saúde de quinta economia do mundo. Não vai se sentir parte se não tiver um Sistema Único de Saúde que seja o Sistema Único de Saúde de quinta economia do mundo. Então, acho que esse é o nosso principal desafio. 
Trazer de fato a saúde, cada esforço de cada um de nós, para o centro da agenda nacional de desenvolvimento do País.

Chioro dos Reis (2014, p. 4) expôs desafios que seriam mais importantes, priorizando o projeto iniciado por seu antecessor:

\begin{abstract}
Manteremos tudo aquilo que o Ministro Padilha vem conduzindo brilhantemente, mas temos o desafio - e foi essa a encomenda mais importante que recebi da Presidenta Dilma - de aprimorar ainda mais os processos em curso, de inovar onde for preciso, de ir além. Não assumo o ministério apenas para completar um ciclo temporal. Tenho a missão, que me foi confiada pela Presidenta Dilma - extremamente difícil -, de aprofundar e ampliar o excelente trabalho efetuado pelo Ministro Padilha.
\end{abstract}

Castro (2015, p. 12/20) apresentou dois desafios principais: “[...] a necessidade de a Administração Pública se modernizar para dar conta de executar seus serviços de maneira ágil e com qualidade e a de aprofundar as estruturas do SUS", acrescentando: "[...] assumo o desafio de, junto com todos, melhorar o nível de saúde da população brasileira. Vim para me unir a vocês nessa missão!".

No governo Dilma, os desafios expressos seguiram a lógica da vinculação da maior qualidade do sistema de saúde à proposta econômica nacional desenvolvimentista, bem como ao aprimoramento, aperfeiçoamento e eficiência, e do ministro como gestor inserido na dinâmica do executivo.

Apesar de a gestão dos ministros da Saúde do governo Dilma terem sido responsáveis pela criação e implementação de ações com impacto positivo à saúde pública, Reis e Paim (2018) argumentam que a agenda da saúde proposta manteve compromissos programáticos que indicaram a continuidade do governo Lula e que as políticas trazidas à tona não propunham inovação significativa nem explicitavam compromisso com ideais da RSB.

Outro desafio identificado foi a permanência do paradigma gerencial nos governos subsequentes ao de FHC, naturalmente transmitido à gestão ministerial e presente nos discursos de posse dos ministros da Saúde. Paula (2005) afirma que se esperava do governo Lula a adoção de uma lógica administrativa societal, alternativa à visão gerencialista do governo FHC, mas, embora tenha havido aberturas nesse alinhamento, foi sem a tenacidade e a prioridade desejadas.

\title{
3.3 Propostas definidas
}

A análise dos discursos de posse possibilitou perceber as propostas apresentadas pelos ministros procuraram essencialmente dar identidade à agenda da gestão.

Albuquerque foi mais econômico e pouco objetivo nas propostas concretas de sua gestão; à época, dizia à imprensa que o problema da saúde não seria a "falta de recursos, mas sim o modo de administrá-los" (ELIAS, 1997, p. 205). Em seu discurso de posse, afirmou: 
de uma administração eficiente, incrementar o combate ao desperdício, às fraudes e à ociosidade, assim fazendo render o máximo de recursos que dispomos, assegurando que cada real gasto na saúde produza o máximo de resultados para o cidadão (ALBUQUERQUE, 1997, p. 2).

Para racionalizar os recursos, uma das medidas de sua gestão foi um projeto encaminhado à Câmara dos Deputados em 1997, tentando um ressarcimento ao SUS dos recursos gastos no atendimento a clientes de planos de saúde. A proposta não se consolidou, mas consistia em criar um fundo público-privado de cerca de $\mathrm{R} \$ 3$ bilhões para financiar tratamentos de alto custo, que os planos de saúde não cobriam e cuja despesas ficavam a cargo do SUS (COSTA, R., 2002).

Serra (1998, p. 5) mostrou-se um pouco mais pragmático: "O primeiro consiste na formação de equipes de saúde da família compostas por um médico, dois auxiliares de enfermagem e seis agentes municipais de saúde, com vistas a atenderem mais ou menos mil famílias cada. Já temos no Brasil 1.600 equipes”. Além disso, dirigiu sua atenção à saúde suplementar:

Temos de transformar a Qualidade do atendimento à saúde numa verdadeira obsessão nacional. Convidaremos mesmo cada grande empresa brasileira que já tenha obtido excelência em qualidade para implantar e supervisionar métodos de qualidade total em um hospital público (SERRA, 1998, p. 6).

Entre 1998 e 2001, na gestão Serra, o Ministério da Saúde passou a se constituir como uma força política de fato, ou, melhor dizendo, um importante ativo político de negociação e projeção, posto que, até então, fora um ministério importante e estratégico, embora menos representativo. Isso não foi acidental. Além do apelo público pela melhoria de condições de saúde naquelas circunstâncias, entre nomes como o de Pedro Malan e Paulo Renato de Souza como potenciais sucessores de FHC, Serra foi o escolhido, mostrando a posteriori o respaldo presidencial à gênese e implementação de amplas políticas federais em sua gestão (COSTA, R., 2002).

Como afirmou em seu discurso, a proposta de ampliação do Programa de Saúde da Família (PSF) foi uma de suas muitas ações, como as voltadas a agências de regulação, medicamentos genéricos, tabaco e AIDS (PASCH et al., 2006). No caso do PSF, que ampliou as ações do Programa de Agentes Comunitários (PAC) entre 1996 e 2000, aumentaram as equipes, de 2.000 para 7.981, e os agentes comunitários de saúde, de 34.000 para 128.000 (DRAIBE, 2003).

Negri (2002, p. 3/4) referiu-se várias vezes à austeridade financeira e orgânica da gestão, reafirmando sequência às ações da gestão Serra: "Não medirei esforços, ainda, para aumentar o número de equipes do Programa Saúde da Família" e "Darei prioridade absoluta ao aumento e diversificação da oferta de medicamentos genéricos no mercado".

Lima (2003, p. 8) manteve o padrão de seus antecessores, indicando as fragilidades sobre as quais agiria, numa lógica programática, mas sem propostas concretas ou claras, exceto quando 
assumiu “[...] o compromisso de realizarmos, se possível ainda este ano, uma Conferência Nacional de Saúde extraordinária para fazermos um balanço desses anos do Sistema Único de Saúde e ao mesmo tempo pensarmos o momento seguinte". De fato, foi a única proposta de seu discurso de posse que mais tarde veio a se concretizar (ARAÚJO, 2017).

Analisando a dinâmica da gestão da Saúde no primeiro mandato do presidente Lula, com Lima no Mistério, Teixeira e Paim (2005) afirmaram que a perspectiva de nova correlação de forças à época representava uma oportunidade de o projeto da RSB ser retomado e reinserido na agenda das políticas públicas do país. Todavia, principalmente após a gestão de Lima, os ganhos setoriais no desenvolvimento do SUS não foram suficientes para fazer avançar o processo da Reforma Sanitária.

Temporão (2007, p. 5) apresentou 22 propostas definidas; por exemplo, "Instituir a Política Nacional de Atenção à Saúde do Homem” e, para a saúde reprodutiva:

8. Fortalecer a Política Nacional de Direitos Sexuais e Reprodutivos, com ênfase na melhoria da atenção obstétrica, no combate ao câncer ginecológico (a situação do câncer de colo de útero é vergonhosa, 20 mil novos casos em 2007), no planejamento familiar, na atenção ao abortamento inseguro e no combate a violência doméstica e sexual; agregando também a prevenção e tratamento de mulheres vivendo com DST/AIDS (TEMPORÃO, 2007, p. 5).

Embora se considere que ele travou embates com a grande mídia, entende-se que ele foi perspicaz em usar a importância da mídia na sociedade e expor sua gestão, imbuído da convicção progressista do pensamento social de saúde. Mais tarde, numa entrevista, afirmou que "as relações com a mídia sempre foram um dos maiores desafios", o que leva a crer que essa relação era orientada pela premissa de enfrentamento, que levava em conta "a importância da construção de uma consciência política coletiva no sentido da consciência sanitária de Berlinguer, para garantir a sustentabilidade política do SUS" (TEMPORÃO, 2018, p. 2063).

Outra proposta de seu discurso de posse foi a Política Nacional da Saúde do Homem (PNSH), regulamentada por portarias do Ministério da Saúde publicadas entre 2009 e 2011, que orientou sua implementação nas 27 unidades federadas, em 132 municípios (SCHWARZ et al., 2012). Anos depois, Temporão contou que, preparando seu discurso de posse, foi uma proposta que decidiu inserir, pois achava necessário dar enfoque e, consequentemente, enfrentar durante a gestão (HEMMI, 2019).

Padilha (2011, p. 8/9) fez propostas definidas, aludindo a um pedido da própria presidenta: “[...] o mais rápido possível, a gente possa implantar no Aqui Tem Farmácia Popular a gratuidade de medicamentos para hipertensos e diabéticos em todo o país". Além disso, propunha o que posteriormente tornou-se um programa federal se saúde, pois já considerava: " $O$ esforço que foi feito em buscar trazer e ter espaços abertos para médicos estrangeiros no país. Todas as medidas têm que ser discutidas e nós temos que ter espaço aberto para isso".

Chioro dos Reis (2014, p. 4) pontuou algumas propostas, mas calcou seu discurso na 
continuidade de ações da gestão anterior: "Sem perder a noção de prioridade para o Programa Mais Médicos, investiremos também nas demais categorias de nível superior e técnico, em especial valorizando a enfermagem e os Agentes Comunitários de Saúde”. No discurso dos dois ministros do governo Dilma, ambos membros do PT, mencionou-se a necessidade da oferta de profissionais médicos no SUS, e Padilha incluiu médicos de outros países. Chioro se comprometeu a expandir esse programa, criado na gestão anterior.

Desde a $9^{a}$ Conferência Nacional de Saúde, em 1992, havia a indicação de uma Política Nacional de Recursos Humanos em Saúde, e, em 2011, pesquisa do Instituto de Pesquisa Econômica Aplicada (IPEA) mostrou que o déficit desses profissionais era um dos principais problemas apontados pelos usuários do SUS. Assim, em 2013, algo que era embrionário no discurso de posse de Padilha foi criado e denominado Programa Mais Médicos, gerando conflitos no governo, além de implementado num ano de efervescência política, pela Medida Provisória n. 621, de 8 de julho de 2013, convertida na Lei n. 12.871, de 22 de outubro de 2013 (ALESSIO; SOUSA, 2017).

Castro (2015, p. 10) trouxe à discussão algumas propostas, referindo-se à criação de determinadas políticas, mas também sem muito direcionamento ou pragmatismo, exceto em: “A minha proposta será de instituir a contribuição permanente para a Seguridade Social, a CPMF, de forma a tornar a saúde segura em seu financiamento e a garantir aos municípios e estados metade do que a União arrecadar na partilha desses recursos". ${ }^{20(10)}$ Apesar disso, centrou a descrição de propostas articuladas em torno de ideias e perspectivas:

Nosso propósito é de aperfeiçoamento das relações público-privadas,
exercendo o Poder Público o seu papel de regulador, fiscalizador e controlador
do setor privado, não devendo ser permitido que o Poder Público atue como
complementar do privado, numa inversão de papéis (CASTRO, 2015, p. 16).

A CPMF é a contribuição provisória sobre movimentação financeira, imposto de 22 de outubro de 1996 regulamentado pela Lei n. 9.311, com recolhimento da alíquota de 0,20\%, legalmente garantido até meados de 2007 (COSTA, R., 2002; FRANÇA; COSTA, N., 2011). Em entrevista à época, Castro afirmou a necessidade do referido tributo, "dividindo tudo do que for arrecadado da CPMF 50\% para a seguridade social do governo e 50\% para a saúde - 25\% para os estados e 25\% para os municípios" (PASSARIHO; MATOSO; ALEGRETTI, 2015, p. 1).

Discutir o financiamento da saúde no Brasil é muito desgastante no contexto do capitalismo contemporâneo (MENDES; CARNUT; GUERRA, 2018). Os 30 anos do SUS têm sido marcados pela persistência de parcos recursos, um subfinanciamento estrutural histórico (MENDES; CARNUT, 2018). Mas, se se aplicasse o art. 55 das Disposições Constitucionais Transitórias da Constituição Federal, 30\% dos recursos da Seguridade Social seriam destinados à saúde - o que nunca aconteceu (MARQUES; MENDES, 2005).

Em 1997, Adib Jatene, idealizador da CPMF, afirmou que ela foi desviada de sua função 
original, passando a servir ao equilíbrio das contas governamentais, o que, dado o subfinanciamento do sistema (COSTA, R., 2002), vai de encontro à afirmação de que considerou a CPMF a fonte mais importante de financiamento do gasto federal em saúde, com cerca de $30 \%$ dos recursos alocados pela União (FRANÇA; COSTA, N., 2011), sendo que no período entre 1995 e 2015, Mendes (2014) constatou que o gasto do Ministério da Saúde não foi alterado, mantendo-se em $1,7 \%$ do produto interno bruto (PIB), enquanto o gasto com juros da dívida representou, em média, 7,1\%.

Quanto às propostas identificadas, exceto Albuquerque, que calcou seu discurso numa lógica abstrata e inespecífica, os outros ex-ministros, menos e mais, propuseram ações concretas que pretendiam implementar e/ou aperfeiçoar. Nos discursos de Serra, Padilha e Temporão, a descrição das propostas foi mais elaborada e desenvolvida, tanto que, anos depois, algumas foram implementadas.

Além do tempo de permanência acima da média em relação aos outros ministros - Serra, Temporão e Padilha, começaram no início do mandato presidencial de FHC, Lula e Dilma, respectivamente, de modo que esses três apresentaram construção e elaboração discursiva, permeada por desafios e propostas mais consolidados e explícitos, do que os que ficaram menos tempo no cargo, fosse por questões de interinidade ou de tensionamento político.

Não se pode afirmar que pelo fato de começar o mandato elaboraram um discurso mais estruturado, dado que a instabilidade a frente do cargo ministerial é uma variável contínua, acrescido ainda o perfil técnico-político de cada personalidade, todavia possivelmente essas escolhas em começo de gestão, como a história recente mostra, provavelmente em meio à coalizão política eles possuíam mais respaldo e convicção dos chefes executivos que os escolheram, o que no nosso entendimento justifica uma maior autonomia e prospecção de planos futuros, sustentáculo de uma construção discursiva com mais liberdade e elaboração.

Essa questão em específico vai ao encontro dos achados de Ferraz e Azevedo (2011), que se dedicaram a estudar o tempo de permanência média de ministros da saúde do Brasil, identificando o quanto seus mandatos são reduzidos, pois em muitas situações, apesar do bom desempenho são descontinuados do cargo, contrariando a urgente necessidade de mandatos mais longos, que viabilizem e contemplem o planejamento de saúde a longo prazo, uma vez que, em comparação à sistemas de saúde de países com IDH (Índice de Desenvolvimento Humano) elevados, o tempo médio dos mandatos dos ministros brasileiros foram consideravelmente inferiores.

Outro ponto a se ponderar no presente estudo é que, embora não se pretenda generalizar e homogeneizar os ministros representantes de ambos partidos (PT e PSDB), pois como afirmou Freitas (2018), apesar das divergências de seus programas formadores, havia entre ambos até 1992 um diálogo e porque não dizer uma "aproximação ideológica", foi após a gestão de José Serra, que à época já apresentou um discurso de posse mais estruturado que o seu antecessor, que 
a pasta da saúde começa a se posicionar, menos como um problema e mais como um capital político ativo, cujo nível de aperfeiçoamento e assinatura pessoal começaram a fazer parte dos discursos seguintes.

Percebeu-se assim, que apesar de todos discursos analisados guardarem similaridades na construção, o aprofundamento e proposições se tornaram mais complexas e mais ambiciosos nos discursos subsequentes, ocupando paulatinamente mais protagonismo por parte desses atores recém-nomeados, já que além de influenciadores e tomadores de decisões, tornaram-se responsáveis em liderar e direcionar ações, com foco na agregação de valor ao sistema de saúde brasileiro (FERRAZ e AZEVEDO, 2011).

Ainda assim, dentre muitas variáveis em um presidencialismo de coalização, regido por interesses econômicos e de ordens diversas, embora entenda uma transformação natural acerca dos posicionamentos discursivos, afirma-se que não houve grandes discrepâncias de posicionamentos conceituais entre o primeiro e o último discurso ministerial analisado, uma vez que os posicionamentos em torno da Saúde Pública e do SUS foram mais retóricos, reativos e conjecturais, alinhados à agenda presidencial, sem o anúncio esperado de uma Política de Estado Suprapartidária, com investimentos à altura das suas reais necessidades e situando-a mais próxima dos anseios de acessibilidade e universalidade, defendidos pelos entusiastas do projeto da RSB.

Nesse sentido, Paim (2018) afirma que os projetos democrático-populares não foram privilegiados pelos atores políticos que tiveram a oportunidade de ocupar o governo federal após a promulgação da dita Constituição Cidadã. Segundo Paim (2008), desde o governo FHC, marcado pelo ajuste macroeconômico das políticas de estabilização monetária e privatização, teve início uma reforma do Estado na contramão da reforma democrática postulada pelo projeto da RSB, continuada pelos governos do PT; por exemplo, no governo Dilma, o foco foram a redução dos gastos públicos e a manutenção do subfinanciamento, com expansão e fortalecimento do setor privado.

Apesar das constatações expostas nos últimos parágrafos, pondera-se que a partir dos conteúdos discursivos dos ex-ministros analisados, sobretudo em suas propostas definidas, assim como destacou Monteiro (2018), houve uma potencial transformação do sistema de saúde brasileiro, que apesar das diversas forças político-ideológicas que marcam o seu campo de disputa e que boicotaram a sua consolidação, estruturando-o como um sistema segmentado, em que convivem o SUS, o sistema de desembolso direto e o sistema de saúde suplementar, as conquistas e avanços são inumeráveis e, dentre elas, cita-se a consolidação do reconhecimento público acerca do direito à saúde, além da expansão e estruturação do SUS.

Portanto a linha de pensamento emitida a partir da presente investigação, não é de conformismo, todavia há que ser realista com base nos avanços e permanências identificadas e rupturas ainda a serem realizadas, pois acredita-se que é necessário nesse momento fazer uma "análise do possível", mais ponderada, cientes obviamente de que poderíamos ter avançado em 
muitos pontos, sobretudo em prol da ampliação e qualidade do sistema, mas não descartando o quanto o sistema de saúde se aperfeiçoou e se ampliou, tanto que nesse período, o Brasil descentralizou atribuições e recursos, aumentando a oferta e o acesso aos serviços e as ações em saúde, melhorando os níveis de saúde (PAIM, 2008, 2013), mas sem dúvida o fato concreto é que o SUS foi implantado, mas não consolidado (PAIM, 2018).

\section{CONCLUSÕES}

Os discursos se assemelham em formato e conteúdo, com similaridades estruturais, atinentes ao rito cerimonial simbólico em que foram proferidos, e, embora estivessem alinhados com uma comunicação protocolar, midiática e política, a produção da narrativa se atrelou, entre outras coisas, ao projeto de governo, à agenda governamental, à demanda do grupo político de sua filiação e à trajetória pessoal, concluindo que essa produção também foi coletiva, respondendo a expectativas ideológicas e sociais.

Não se identificaram grandes rupturas no pensamento sobre saúde entre as plataformas de governos do PT e do PSDB, apenas enfoques diferentes, com manutenção de uma linha de gestão operacional similar, subordinada à lógica econômica de produção de saúde.

Afirma-se que, de Albuquerque a Lima, o conteúdo discursivo revelou permanências na projeção de medidas que consolidassem o sistema, garantissem sua paulatina descentralização e, consequentemente, mínimas condições de acesso à saúde para todos os brasileiros, questões que estiveram presentes nos discursos dos ministros que os sucederam; todavia, foram menos prioritárias, fosse pelo aperfeiçoamento e pela consolidação do sistema em inúmeros aspectos, fosse pela necessidade de atender a novas demandas, consoante com o momento político e a realidade socioeconômica.

Mesmo com suas diferenças partidárias e de origem técnica, a trajetória profissional e política da maioria dos ex-ministros da saúde esteve alinhada com a defesa da saúde como um direito do cidadão e um dever do Estado, princípio básico da RSB. No entanto, os discursos não fazem referência à RSB, o que pode indicar certo cuidado, dadas as múltiplas relações e representações que o cargo executivo de ministro pressupõe numa agenda governamental não raro vinculada às tensões que envolvem interesses econômicos e de outras ordens.

O conteúdo dos conceitos e os desafios apresentados foram mais reveladores do que as propostas, que, em sua maioria, adotou um tom generalista, e, entre as que seguiam uma lógica programática, poucas foram implementadas. Os discursos se alinhavam à agenda de governamental e enunciavam algumas propostas, mas a gênese e a implementação de ações de saúde não obedeceram a uma programação predefinida, contemplando na gestão o que foi anunciado no discurso, porquanto outras variáveis (decisão presidencial, vontade política, prestígio, crises sanitárias, lobbies, apelos setoriais etc.) influenciaram a gestão federal em saúde e a gênese e implementação das ações subsequentes. 
Certamente, nesses discursos ministeriais em que conceitos foram elaborados, desafios sublinhados e propostas definidas, transformações inúmeras foram identificadas, dado que intencionalidades e influências ideológicas diversas permearam esse conflituoso campo. Ainda assim, ficou evidente ao comparar os conteúdos discursivos (conceitos, desafios e propostas) em momentos históricos distintos, que paulatinamente enfoques se diferenciavam e situações eram superadas pelos atores e as gestões das quais faziam parte, de modo que o SUS foi sendo implementado e ampliado, sustentado pela estrutura técnica do Ministério da Saúde, em um contínuo período de estabilidade democrática, cujas ações em sua grande parte, eram liderada por personalidades, que estiveram engajadas em maior ou menor grau com o movimento da RSB em suas trajetórias de vida e que, estiveram comprometidas em uma atuação minimamente compatível com os interesses republicanos, expressos em seus discursos e praticados em suas gestões.

Os resultados apresentados neste artigo integram uma pesquisa ampla, que analisa relações envolvendo os ministros da Saúde no Brasil e sua influência no SUS da perspectiva da análise documental e história oral. Espera-se que esta iniciativa estimule o desenvolvimento de estudos que porventura se proponham a analisar discursos não apenas no campo da saúde e mesmo guiados por diferentes perspectivas teórico-metodológicas.

\section{REFERÊNCIAS}

ABBAGNANO, Nicola. Dicionário de Filosofia. São Paulo: Martins Fontes, 1998.

ALBUQUERQUE, Carlos Cesar Silva de. Discurso de Posse do Ministro da Saúde. Brasília, DF: Ministério da Saúde, mar. 1997. Divulgação n. 7.

ALESSIO, Maria Martins; SOUSA, Maria Fátima de. Programa Mais Médicos: elementos de tensão entre governo e entidades médicas. Interface, Botucatu, v. 21, supl. 1, p. 1143-1156, 2017. doi: https://doi.org/10.1590/1807-57622016.0396.

ARAÚJO, Carmen Emmanuely Leitão. Estado e mercado, continuidade e mudança: a dualidade da política de saúde nos governos FHC e Lula. Tese (Doutorado em Ciência Política) - Faculdade de Filosofia e Ciências Humanas, Universidade Federal de Minas Gerais, Belo Horizonte, 2017. Disponível em: https://repositorio.ufmg.br/bitstream/1843/BUOSB33M3G/1/tese_dcp_ufmg_carmem_leit_o_biblioteca_arial.pdf. Acesso em: 8 mar. 2021.

BRASIL. MINISTÉRIO DA SAÚDE. Galeria dos Ministros. 2014. Disponível em: <http://bvs.saude.gov.br/promocao-da-saude-3/83-galeria-dos-ministros〉. Acesso em: 10 out. 2020 .

BRASIL. CÂMARA DOS DEPUTADOS. Decreto n. 70.274, de 9 de março de 1972. Aprova as normas do cerimonial público e a ordem geral de precedência. Brasília, DF: Câmara dos Deputados, 1972. Disponível em: https://www2.camara.leg.br/legin/fed/decret/19701979/decreto-70274-9-marco-1972-418937-norma-pe.html. Acesso em: 8 mar. 2021.

CASTRO, Marcelo. Discurso: Marcelo Castro, Ministro da Saúde, 6 out. 2015. Disponível em: https://portalarquivos.saude.gov.br/images/pdf/2015/outubro/06/. Acesso em: 10 out. 2020.

CHARAUDEAU, Patrick. Discurso político. São Paulo: Contexto, 2018.

COSTA, Ricardo Cesar Rocha da Costa. Descentralização, financiamento e regulação: a 
reforma do sistema público de saúde no Brasil durante a década de 1990. Revista de Sociologia e Política, n. 18, p. 49-71, 2002. doi: https://doi.org/10.1590/S0104-44782002000100005.

DRAIBE, Sônia. A política social no período FHC e o sistema de proteção social. Tempo Social, v. 15, n. 2, p. 63-101, 2003. doi: http://dx.doi.org/10.1590/S0103-20702003000200004.

ELIAS, Paulo Eduardo. Reforma ou contra-reforma na proteção social à saúde. Lua Nova, $n$. 40-41, p. 193-215, 1997. doi: https://doi.org/10.1590/S0102-64451997000200009.

FERRATER-MORA, José. Dicionário de filosofia. São Paulo: Loyola, 2004.

FERRAZ, Marcos Bosi e AZEVEDO, Rafael Teixeira. Ministers of Health: short-term tenure for long-term goals?. Sao Paulo Medical Journal [online]. v. 129, n. 2 pp. 77-84. 2011.

FOUCAULT, Michel. A arqueologia do saber. Rio de Janeiro: Forense Universitária, 2007.

FOUCAULT, Michel. Microfísica do poder. Rio de Janeiro: Graal, 1982.

FRANÇA, José Rivaldo Melo de; COSTA, Nilson do Rosário. A dinâmica da vinculação de recursos para a saúde no Brasil: 1995 a 2004. Ciência \& Saúde Coletiva, v. 16, n. 1, p. 241 257, 2011. doi: https://doi.org/10.1590/S1413-81232011000100027.

FREITAS, Felipe Corral de. O primeiro grande antagonismo entre PSDB e PT. Opin. Pública, Campinas, v 24, n.3, p.547-595, set/dez, 2018.

HEMMI, Ana Paula Azevedo. A Política Nacional de Saúde do Homem por José Gomes Temporão. Interface, Botucatu, n. 23, p. 1-12. Número especial. doi: https://doi.org/10.1590/interface.1810628.

IACOMINI JUNIOR, Franco; CARDOSO, Moisés; PRADO JUNIOR, Tarcis. Os "nós" de Temer: uma análise dos discursos de posse de 2016. Compolítica, v. 8, n. 1, p. 66-95, 2018. doi: https://doi.org/10.21878/compolitica.2018.8.1.139.

LIMA, Humberto Sérgio Costa. Discurso de posse: ministro da Saúde Humberto Costa, 2003. Disponível em:

http://webcache.googleusercontent.com/search?q=cache:XZu8nepZjoJ:www1.uol.com.br/ferna ndorodrigues/030106/discurso_de_possesaude.doc+\&amp;cd=1\&amp;hl=pt-

BR\&amp;ct=clnk\&amp;gl=br. Acesso em: 10 out. 2020.

MACULAN, Benildes Coura Moreira dos Santos; LIMA, Gracinda Angela Borém de Oliveira. Buscando uma definição para o conceito de "conceito". Perspectivas em Ciência da Informação, v. 22, n. 2, p. 54-87, 2017. doi: https://doi.org/10.1590/1981-5344/2963.

MAINGUENEAU, Dominique. Discurso e análise do discurso: uma introdução. São Paulo: Parábola, 2014.

MARQUES, Rosa Maria; MENDES, Áquilas. SUS e seguridade social: em busca do elo perdido. Saúde e Sociedade, v . 14, n. 2, p. 39-49, 2005. doi: https://doi.org/10.1590/S010412902005000200005.

MENDES, Áquilas. O fundo público e os impasses do financiamento da saúde universal brasileira. Saúde e Sociedade, v. 23, n. 4, p. 1183-1197, 2014. doi: https://doi.org/10.1590/S0104-12902014000400006.

MENDES, Áquilas; CARNUT, Leonardo. Capitalismo contemporâneo em crise e sua forma política: o subfinanciamento e o gerencialismo na saúde pública brasileira. Saúde e Sociedade, v. 27, n. 40, p. 1105-1119, 2018. doi: https://doi.org/10.1590/s0104-12902018180365.

MENDES, Áquilas; CARNUT, Leonardo; GUERRA, Lucia Dias da Silva. Reflexões acerca do financiamento federal da Atenção Básica no Sistema Único de Saúde. Saúde em Debate, v. 42, p. 224-243, 2018. Número especial. doi: https://doi.org/10.1590/0103-11042018s115.

MINAYO, Maria Cecília de Souza. O desafio do conhecimento: pesquisa qualitativa em saúde. São Paulo: Hucitec, 2006. 
MONTEIRO, Maria Gabriela. A mudança de direção nas políticas públicas: atores e estratégias ocultas na implementação do Sistema Único de Saúde. In: FLEURY, Sônia. Teoria da reforma Sanitária: Diálogos Críticos. Rio de Janeiro: Fiocruz, 2018, p.247-290.

NEGRI, Barjas. Discurso de posse: ministro da Saúde. Saúde com justiça: um compromisso a ser mantido, p. 3-7, 2002. Disponível em:

http://bvsms.saude.gov.br/bvs/publicacoes/saude_justica.pdf. Acesso em: 10 out. 2020.

PADILHA, Alexandre Rocha Santos. Discurso: posse do Ministro da Saúde Alexandre Padilha. Centro Brasileiro de Estudos de Saúde, 2011. Disponível em:

http://cebes.org.br/2011/01/integra-do-discurso-do-ministro-da-saude-alexandre-padilhadurante-a-cerimonia-de-transmissao-de-cargo/. Acesso em: 10 out. 2020.

PAIM, Jairnilson Silva. Sistema Único de Saúde (SUS) aos 30 anos. Ciência \& Saúde Coletiva, v. 23, n. 6, p. 1723-1728, 2018. doi: https://doi.org/10.1590/141381232018236.09172018 .

PAIM, Jairnilson Silva. Reforma Sanitária Brasileira (RSB): expressão ou reprodução da revolução passiva? Planejamento e Políticas Públicas, n. 49, p. 15-33, 2017. Disponível em: http://repositorio.ipea.gov.br/handle/11058/8227. Acesso em: 8 mar. 2021.

PAIM, Jairnilson Silva. A Constituição Cidadã e os 25 anos do Sistema Único de Saúde (SUS). Cadernos de Saúde Pública, v. 29, n. 10, p. 1927-1936, 2013. doi: https://doi.org/10.1590/0102-311X000995.

PAIM, Jairnilson Silva. A reforma sanitária brasileira e o Sistema Único de Saúde: dialogando com hipóteses concorrentes. Physis, v. 18, n. 4, p. 625-644, 2008. doi: https://doi.org/10.1590/S0103-73312008000400003.

PASCH, Dário Frederico; RIGHI, Liane Beatriz; THOMÉ, Henrique Inácio; STOLZ, Eveline Dischkaln. Paradoxos das políticas de descentralização de saúde no Brasil. Revista Panamericana de Salud Pública. v. 20, n. 6, p. 416-22, 2006. Disponível em: https://scielosp.org/article/rpsp/2006.v20n6/416-422/. Acesso em: 8 mar. 2021.

PASSARINHO, Nathalia; MATOSO, Felipe; ALEGRETTI, Laís. Novo ministro quer CPMF permanente e com repasse para a Saúde. G1, Brasília, 2 out. 2015. Política. Disponível em: http://g1.globo.com/politica/noticia/2015/10/novo-ministro-da-saude-quer-cpmf-eterna-e-comrepasse-para-o-setor.html. Acesso em: 1 nov. 2020.

PAULA, Ana Paula Paes de. Administração pública brasileira entre o gerencialismo e a gestão social. Revista de Administração de Empresas, v. 45, n. 1, p. 36-49, 2005. doi: https://doi.org/10.1590/S0034-75902005000100005.

PIMENTEL, Pedro Chapaval; PANKE, Luciana. Discursos diplomáticos: objeto de pesquisa da Comunicação Política?. Intercom, v. 43, n. 2, p. 53-71, 2020. doi: http://dx.doi.org/10.1590/1809-5844202023.

PISTORI, Maria Helena Cruz. Ethos e pathos no discurso do Ministro-Relator do Supremo Tribunal Federal. Bakhtiniana, v. 13, n. 1, p. 71-93, 2018. doi: https://doi.org/10.1590/2176457334855.

REIS, Ademar Arthur Chioro dos. Discurso de posse: ministro da Saúde Arthur Chioro, 3 fev. 2014. Disponível em:

http://idisa.org.br/img/File/DISCURSO\%20DE\%20POSSE\%20CHIORO.pdf. Acesso em: 10 out. 2020.

REIS, Camila Ramos; PAIM, Jairnilson Silva. A saúde nos períodos dos governos Dilma Rousseff (2011-2016). Divulgação em Saúde para Debate, Rio de Janeiro, n. 58, p. 101-114, 2018. Disponível em:

https://repositorio.ufba.br/ri/bitstream/ri/29852/1/Artigo\%20Jairnilson\%20Paim.\%202018.pdf. Acesso em: 8 mar. 2021. 
SCHIFFRIN, Deborah. Approaches to discourse. Oxford/Cambridge: Blackwell, 1994.

SCHWARZ, Eduardo, GOMES, Romeu; COUTO, Márcia Thereza; MOURA, Erly Catarina de; CARVALHO, Sarah de Araújo; SILVA, Simione Fátima Cesar da. Política de saúde do homem. Revista de Saúde Pública, v. 46, supl. 1, p. 108-116, 2012. doi:

https://doi.org/10.1590/S0034-89102012005000061.

SERRA, José. Discurso de posse: ministro José Serra, no Ministério da Saúde. A reforma administrativa do sistema de saúde, n. 13, p. 28-37, 1998. Disponível em:

http://www.bresserpereira.org.br/documents/mare/cadernosmare/caderno13.pdf. Acesso em: 10 out. 2020.

TEIXEIRA, Carmen Fontes de Souza; PAIM, Jairnilson Silva. A política de saúde no governo Lula e a dialética do menos pior. Saúde em Debate, Rio de Janeiro, v. 29, n. 71, p. 268-283, 2005. Disponível em: https://www.redalyc.org/pdf/4063/406345256005.pdf. Acesso em: 8 mar. 2021.

TEMPORÃO, José Gomes. Entrevista com o ex-ministro da Saúde José Gomes Temporão.

Ciência \& Saúde Coletiva, v. 23, n. 6, p. 2061-2068, 2018. doi: https://doi.org/10.1590/141381232018236.05642018 .

TEMPORÃO, José Gomes. Discurso de posse: Dr. José Gomes Temporão, ministro da Saúde, 19 mar. 2007. Disponível em:

http://www5.ensp.fiocruz.br/biblioteca/dados/arq5068.pdf. Acesso em: 10 out. 2020.

Artigo submetido em: 2021-06-09

Artigo reapresentado em: 2021-06-21

Artigo aceito em: 2021-02-30 